\title{
Effects of light on cell growth, chlorophyll, and carotenoid contents of Chlorella sorokiniana and Ankistrodesmus falcatus in poultry dropping medium
}

\author{
Jane Chizie Ogbonna, Nkechinyere Onyekwere Nweze, Christiana Nwakego Ogbonna* \\ Department of Plant Science and Biotechnology, University of Nigeria, Nsukka, Nigeria.
}

\begin{tabular}{|c|c|}
\hline ARTICLE INFO & ABSTRACT \\
\hline $\begin{array}{l}\text { Article history: } \\
\text { Received on: October } 08,2020 \\
\text { Accepted on: December 26, } 2020 \\
\text { Available online: March 14, } 2021\end{array}$ & $\begin{array}{l}\text { Microalgae biomass and their products are invaluable bio-resources with numerous applications in food, feed, } \\
\text { pharmacy, cosmetics, and environments. The effects of light intensities on biomass, chlorophyll-a, and total } \\
\text { carotenoid production by Chlorella sorokiniana and Ankistrodesmus falcatus were studied in Bold's Basal Medium } \\
\text { (BBM) and Poultry Medium (PM) as the growth media. The growth of C. sorokiniana and A. falcatus increased }\end{array}$ \\
\hline $\begin{array}{l}\text { Key words: } \\
\text { Microalgae, } \\
\text { Biomass, } \\
\text { Chlorella sorokiniana, } \\
\text { Ankistrodesmus falcatus, } \\
\text { Light intensity, } \\
\text { Chlorophyll, } \\
\text { Carotenoids. }\end{array}$ & $\begin{array}{l}\text { with increase in light intensity in PM and was inhibited at } 1786 \text { lux in } C \text {. sorokiniana in BBM. PM supported higher } \\
\text { biomass production by } C \text {. sorokiniana than BBM while it was the reverse for } \text { A. falcatus. A. falcatus produced higher } \\
(P \leq 0.05) \text { concentrations of chlorophyll-a than } C \text {. sorokiniana in both media. The highest carotenoid concentration } \\
\text { of } 11.84 \mathrm{mg} / \mathrm{g} \text {-biomass was accumulated by } C \text {. sorokiniana in PM as against } 7.027 \mathrm{mg} / \mathrm{g} \text {-biomass obtained in BBM. } \\
\text { On the other hand, the highest carotenoid concentration of } 7.633 \mathrm{mg} / \mathrm{g} \text {-biomass was accumulated by } A \text {. falcatus in } \\
\text { BBM as against } 4.299 \mathrm{mg} / \mathrm{g} \text {-biomass obtained in PM. It is interesting to note in the present study that a cheap medium } \\
\text { such as PM supported higher biomass and carotenoid production by } C \text {. sorokiniana than BBM. }\end{array}$ \\
\hline
\end{tabular}

\section{INTRODUCTION}

Food insecurity and need for functional foods have been increasing due to rapid population growth. It is especially true for the developing countries where majority of the populace live under poverty level and are thus malnourished. There is therefore an urgent need to explore alternative sources of cheap and nutritionally rich foods.

Microalgae are very good sources of proteins [1-3], carbohydrates [4], carotenoids [5-7], chlorophylls [8-10], and a variety of vitamins and pro-vitamins depending on the species and culture conditions [3,11-13]. Many species also accumulate high concentrations of various forms of lipids (both saturated and unsaturated) that can be converted to biodiesel [14] or used as functional food supplements to combat hunger and diseases [15]. Many species of microalgae therefore have great potentials as foods and food supplements.

Another important characteristic of microalgae is that they are ubiquitous with high photosynthetic efficiency and high growth rates [16-18]. Thus, their productivities can be orders of magnitude higher than those of the higher plants. They can be cultivated all the

*Corresponding Author:

Christiana Nwakego Ogbonna, Department of Plant Science and

Biotechnology, University of Nigeria, Nsukka, Nigeria.

E-mail: christiana.ogbonna@unn.edu.ng year round and even in places that are not suitable for conventional agriculture. In comparison with other microorganisms, they can be cultivated on cheap and easily available media such as agricultural and food processing wastewater. This also means that wastewater treatment can be coupled with production of microalgae biomass and metabolites for various applications [19,20]. Metabolite production from microalgae is environmentally friendly since they use up carbon dioxide for photosynthesis and generate oxygen making their growth activities close to carbon neutral [16,21,22].

Some important species of microalgae such as Spirulina, Chlorella, Nannochloropsis, Phaeodactylum, and Dunaliella are already cultivated for various purposes [2,3]. However, there are still a lot of species that are yet to be evaluated. This is especially true for many African countries where research activities on microalgae are still very low.

Among the important components of microalgae are chlorophylls and carotenoids. Chlorophylls have many useful applications in food industries as colorants and nutraceuticals. They are also applied as ingredients in cosmetics and pharmaceutical preparations as anti-inflammatory, anti-mutagenic [23,24], and antimicrobial agents $[25,26]$. Carotenoids have several health benefits in man and animals and are used as colorants in aquaculture feed, as coloring agent in human food, and as food supplements due to their antioxidative properties. They are used in pharmaceutical 
preparations and costimetics as anti-inflammatory, anti-carcinogenic, and antimicrobial agents $[6,18,27]$.

The demand for natural pigments such as chlorophylls and carotenoids has been increasing with increase in human population and the increased awareness and perceptions of the negative health implications of consuming synthetic pigments [28,29]. The world market price for carotenoid was estimated to be about 1.24 billion US dollars in 2016 and it was estimated to increase up to 1.53 billion dollars by the year 2021 [6,30]. According to the Market Research Report 2019, (Report Code 4411) the carotenoid market price is expected to go up to 2.0 billion USD by the year 2026 [31]. Algal products such as the biomass, chlorophylls, and carotenoids are indispensable components of human and animal diet [32]. Despite, the functionality of microalgae pigments such as chlorophylls and carotenoids (beta-carotene, phycocyanin, astaxanthin, and lutein) as food supplements and colorants, they are still very expensive and not affordable by many poor rural dwellers. Several species of microalgae grow freely at various locations and have the potentials to be employed in the production of useful biomass, chlorophylls, and carotenoids to provide solutions for food, health, and environmental problems of the community/rural dwellers. To make microalgae biomass and pigments cheap and affordable, there is a need to isolate local species and establish their growth on locally available nutrients. It has been estimated that the nutrients required for cultivation, maintenance, and production of metabolites from microalgae contribute up to $50 \%$ of the total production costs $[33,34]$. Thus, the use of agro-industrial wastes in microagal nutrient formulation will go a long way in reducing the production cost and mitigate environmental pollution. As a means of increasing protein supply, poultry farms have been increasing steadily in both numbers and sizes, leading to generation of huge amounts of poultry manure, which when disposed untreated causes a lot of environmental pollution. The composition of poultry manure depends on the type of feed but generally it contains a lot of nitrogen (mainly in form of ammonia), potassium, and phosphorus [34] all of which are essential for the growth of microalgae. Light is also among the most important factor affecting photoautotrophic growth of microalgae. Although Nigeria and most tropic countries have abundant light throughout the year, it is important to optimize light intensity since high light intensities inhibit cell growth and metabolite formation [35].

The aim of this research work was to evaluate the influence of light intensity and poultry waste based growth medium on the production of cell biomass, total chlorophyll, and carotenoid contents by two local microalgae isolates (Chlorella sorokiniana and Ankistrodesmus falcatus).

\section{MATERIALS AND METHODS}

\subsection{Microalgae Species}

Two species of microalgae (C. sorokiniana and A. falcatus) were supplied by Prof. N.O. Nweze of the Department of Plant Science and Biotechnology University of Nigeria, Nsukka. The microalgae species were activated by cultivating in sterilized Bold's Basal Medium (BBM) and Poultry Medium (PM) for 14 days at room temperature $\left(27 \pm 2^{\circ} \mathrm{C}\right)$ using sun light as the light source. They were transferred and maintained in BBM and poultry agar slant cultures. The slants were stored in a refrigerator at $8^{\circ} \mathrm{C}$ and subcultured every 2 weeks into fresh liquid BBM or PM for use in the experiments.

\subsection{Preparation of BBM}

The BBM was prepared according to the methods of Martos [36]. The appropriate volume of the major element stock solution was dispensed into a $2000 \mathrm{ml}$ round bottom flask. One milliliter each of the trace element stock solution and the diluted $\mathrm{H}_{2} \mathrm{SO}_{4}$ were added. The $\mathrm{pH}$ of the medium was adjusted to 6.8 with $0.1 \mathrm{M} \mathrm{NaOH}$ and the volume was made up to $1000 \mathrm{~mL}$ with distilled water. The medium was dispensed in $200 \mathrm{~mL}$ aliquots into $900 \mathrm{~mL}$ flat bottom jars. The jars were plugged with cotton wool, wrapped with aluminum foil and autoclaved at $121^{\circ} \mathrm{C}, 1.0 \mathrm{~atm}$ for $20 \mathrm{~min}$.

\subsection{PM}

Poultry (chicken) droppings were obtained from a poultry farm at the Faculty of Veterinary Medicine, University of Nigeria, Nsukka. The chicken droppings were air dried for $24 \mathrm{~h}$ and $75 \mathrm{~g}$ was dissolved in 11 of tap water. This was made up to 301 and filtered with a cheese cloth to remove debris. The filtrate was left to stand for 2 days and then autoclaved at $121^{\circ} \mathrm{C}$ and $1.0 \mathrm{~atm}$ for $20 \mathrm{~min}$ [37].

\subsection{Light Illumination}

Three rechargeable $592.6 \mathrm{~cm}$ florescent tubes were installed inside a wooden frame and used as a source of light. The intensity of light on the culture surface was varied by varying the distance of the cultures from the florescent tubes. The light intensity was measured using a lux meter (Custom Lux Meter, Model 1x-1000, China). The culture flasks were placed at distances of $3.75 \mathrm{~cm}, 7.75 \mathrm{~cm}$, and $10.75 \mathrm{~cm}$ from the light source. These positions corresponded to 1786 lux, 1307 lux, and 702 lux, respectively.

\subsection{Pre-culture of the Microalgae Species}

Twenty milliliters $(20 \mathrm{~mL})$ of the stock microalgae culture (section 2.1) were used to inoculate $200 \mathrm{~mL}$ of BBM or PM in $900 \mathrm{ml}$ glass jars to activate the microalga cells before the main experiments. The cultures were incubated at room temperature $\left(27 \pm 2^{\circ} \mathrm{C}\right)$ and cultivated for 14 days with intermittent manual shaking twice daily to re-suspend the cell sediments and facilitate oxygen and carbon dioxide transfer.

\subsection{Effects of Light Intensities on the Growth, Chlorophyll-a, and Total Carotenoid Production by $C$. sorokiniana and A. falcatus in Bold's Basal and Poultry Media}

Thirty six glass jars each with a total volume of $900 \mathrm{~mL}$ (section 2.5) were used for the experiment. BBM or PM $(250 \mathrm{~mL})$ was dispensed into each jar, plugged with cotton wool and a sampling tube was inserted into each jar. They were autoclaved at $121^{\circ} \mathrm{C}(1.0 \mathrm{~atm})$ for 15 min. After cooling, 18 of them were inoculated with $50 \mathrm{ml}$ of C. sorokiniana culture with cell concentration of $2 \times 10^{7}$ cells $/ \mathrm{ml}$ while the other 18 jars were inoculated with $A$. falcatus culture with the same cell concentration. For each species of microalgae, three jars were incubated at 702 lux, three at 1307 lux while the other three were incubated at 1786 lux. The cultivation was done inside the wooden box at room temperature $\left(27 \pm 2^{\circ} \mathrm{C}\right)$ for 15 days. Sample $(0.5 \mathrm{~mL}$ each $)$ was withdrawn every 3 days to measure biomass, chlorophyll, and carotenoid concentrations.

\subsection{Analytical Methods}

\subsubsection{Measurement of cell growth}

Cell growth was measured by counting the cells and measuring the optical densities. Hemocytometer was used to count the cell number 
while UV visible spectrophotometer (Shimadzu Model UV-1200, Japan) was used to measure the optical density (OD) at a wavelength of $750 \mathrm{~nm}$.

\subsubsection{Measurement of chlorophyll and carotenoid concentrations \\ 2.7.2.1. Extraction}

Chlorophyll and carotenoids were extracted from wet biomass following a modified method of Becker [38]. Five milliliters $(5 \mathrm{ml})$ of culture broth were centrifuged at $3000 \mathrm{rpm}$ for $15 \mathrm{~min}$ and the supernatant was discarded. The pellet was washed twice by re-suspending in $5 \mathrm{ml}$ of distilled water and centrifuging at 3000 rpm for $10 \mathrm{~min}$. The supernatant was discarded and $3 \mathrm{ml}$ of $90 \%$ methanol was added and vortexed for $5 \mathrm{~min}$ to mix. The mixture was incubated in a water bath at $60^{\circ} \mathrm{C}$ for $60 \mathrm{~min}$. The mixture was then made up to $5 \mathrm{ml}$ with $90 \%$ methanol and centrifuged at $3000 \mathrm{rpm}$ for another $15 \mathrm{~min}$. The supernatant was collected in a clean test tube and used for absorbance reading.

\subsubsection{Measurement of the absorbance}

The extract was diluted with distilled water and the absorbance measured at 470, 650, 655, and $750 \mathrm{~nm}$ using a UV visible spectrophotometer (Shimadzu Model UV-1200, Japan).

\subsubsection{Calculation of the chlorophyll and carotenoid contents}

Chlorophyll-a and total carotenoid contents were calculated from the following equations:

$$
\begin{gathered}
\text { Chlorophyll a; Chl-a }(\mu \mathrm{g} / \mathrm{ml})=16.72 \mathrm{~A}_{660}-9.16 \mathrm{~A}_{650} \\
\text { Chlorophyll b; Chl-b }(\mu \mathrm{g} / \mathrm{ml})=34.09 \mathrm{~A}_{650}-15.28 \mathrm{~A}_{660} \\
\text { Carotenoid; carotenoids }(\mu \mathrm{g} / \mathrm{ml})=\left(1000 \mathrm{~A}_{470}-1.63 \mathrm{chl} \mathrm{a}-104.9\right.
\end{gathered}
$$
chl b)/221.

Where $\mathrm{A}_{660}, \mathrm{~A}_{650}$, and $\mathrm{A}_{470}$ represent absorbance at $660 \mathrm{~nm}, 650 \mathrm{~nm}$, and $470 \mathrm{~nm}$, respectively, Branisa et al. [39].

\subsection{Statistical Analysis}

The experiments were performed in triplicates and the data generated were analyzed by one way analysis of variance. Where there was a significant difference, the means were separated using least significant difference.

\section{RESULTS}

\subsection{Growth in BBM}

As shown in Figure 1, the growth of C. sorokiniana and A. falcatus in $\mathrm{BBM}$ increased with increase in the light intensity. This result agrees with the work of Metsoviti et al. [40], who reported an increase in the growth rate of Chlorella vulgaris with increase in light intensity when cultivated both indoors and outdoors. However, A. falcatus exhibited higher growth in BBM than $C$. sorokiniana with an OD of 1.2 after 15 days at 1786 lux as against OD of 0.85 obtained for $C$. sorokiniana at the same light intensity and cultivation period. At a lower light intensities of 1307 and 702 lux, C. sorokiniana exhibited higher growth rate than Ankistrodesmus with optical densities of 0.8 and 0.65 against 0.7 and 0.4 for Ankistrodesmus, respectively. This result implied that at higher light intensity, the growth of $C$. sorokiniana was inhibited. This agrees with the findings of Nzayisenga et al. [41], who reported that a light intensity of about $150 \mu \mathrm{Em}^{-2} \mathrm{~s}^{-1}$ was the optimal for biomass production by $C$. vulgaris and Scenedesmus obliquus and that increasing the intensity to $300 \mu \mathrm{E} \mathrm{m}^{-2} \mathrm{~s}^{-1}$ was inhibitory to their growth. This result shows that the intensity of light required by the two microalgae differs and that Ankistrodesmus has higher light saturation intensity than Chlorella.

\subsection{Growth in PM}

The growth of the two species of microalgae in PM took a similar pattern with the growth in BBM. Their growth increased with increase in the light intensity. However, PM favored the growth of Chlorella more than Ankistrodesmus. The optical densities were 1.45, 1.33, and 1.12 after 15 days of culturing C. sorokiniana at 1786, 1307, and 702 lux, respectively. The highest OD obtained in A. falcatus was 1.0 as shown in Figure 2. This might be due to the differences in the composition of the two media. PM is known to contain higher nitrogen and other elements than BBM [36,37]. This result agrees with the work of Kumar et al. [42], who reported that nutrient from poultry excrete gave the highest cell growth of their isolate of Chlorella sorokiniana among the four animal wastes they tested. In case of Ankistrodesmus, there are no reports in literature on the effect of media or light intensity on the growth. A comparison of the growth of the two species in PM and BBM is shown in Table 1. At a light intensity of 1307 lux, the growth of both Ankistrodesmus and Chlorella in PM was significantly higher $(P<0.01)$ than in BBM, showing that at that light intensity,

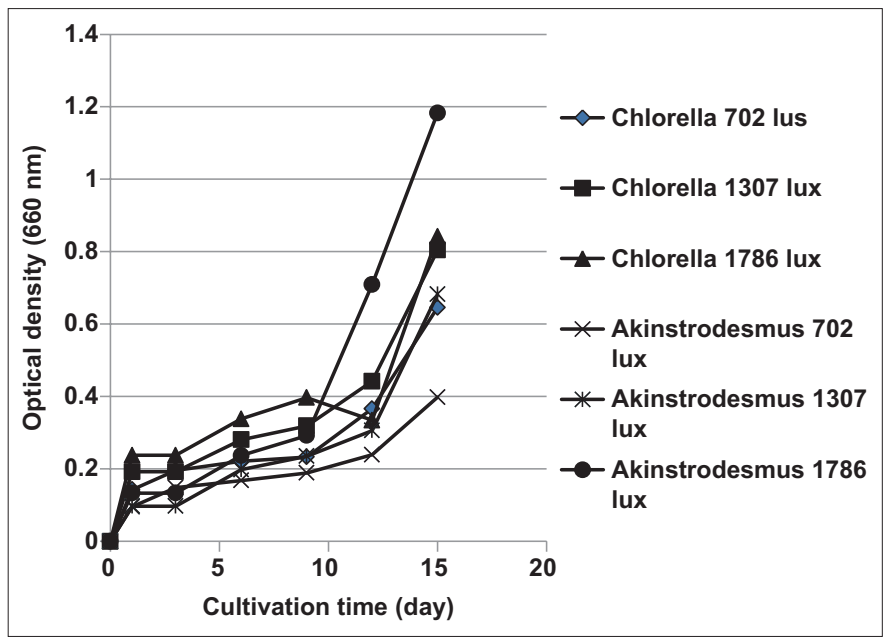

Figure 1: Effect of light intensity on the growth of Chlorella sorokiniana and Ankistrodesmus falcatus in Bold's Basal medium.

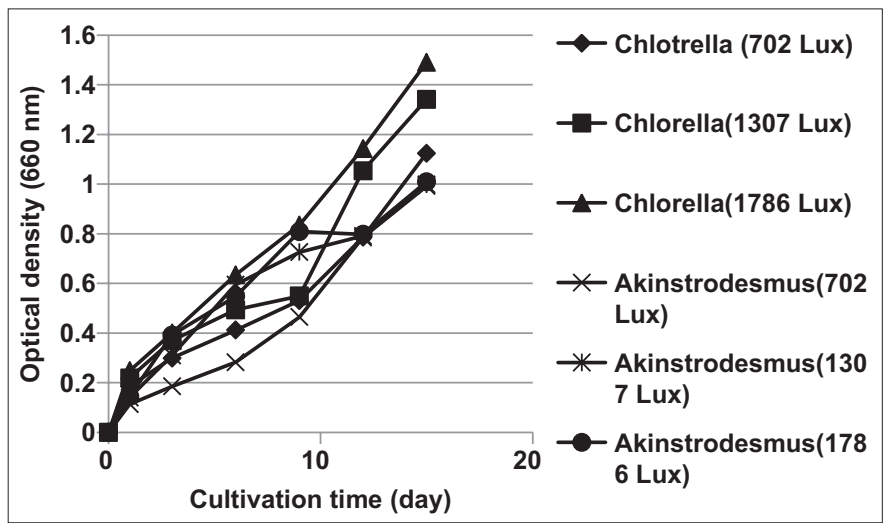

Figure 2: Effect of light intensity on the growth of Chlorella sorokiniana and Ankistrodesmus falcatus in poultry manure. 
nutrients was limiting in BBM. However, at higher light intensity of 1786 lux, there was no significant increase in the growth of both Ankistrodesmus and Chlorella in PM, but there was significant increase in BBM implying that light was already saturating in PM but still limiting in BBM. On the whole, the effects of light intensity on the growth of the two species in PM were not significant, probably due to the turbidity of the medium which affects light absorption.

\subsection{Chlorophyll-a Production in BBM}

The results of the effects of light intensities on chlorophyll-a production by $C$. sorokiniana and A. falcatus in BBM are shown in Figure 3. For the two microalgae cultivated in BBM, biomass harvested after 15 days of growth had higher chlorophyll-a content than the one harvested on the $12^{\text {th }}$-day irrespective of the light intensity. In the case of C. sorokiniana, the highest light intensity (1786 Lux) gave the highest chlorophyll-a content. However, chlorophyll-a contents decreased with increase in light intensity in the case of $A$. falcatus. Hence, the highest chlorophyll-a content in A. falcatus was obtained on day 15 at 702 lux which was the lowest light intensity employed in this study. Although light is important for chlorophyll synthesis, very high light intensities inhibit chloroplast development $[43,44]$. On the whole, the chlorophyll-a contents of A. falcatus were significantly higher $(P<0.05)$ than those of $C$. sorokiniana under all the light intensities investigated.

\subsection{Chlorophyll-a Production in PM}

The results of chlorophyll-a contents of $C$. sorokiniana and A. falcatus in PM are shown in Figure 4. When the two microalgae were cultivated in PM, light intensity did not have any significant effects on the chlorophyll-a contents of $C$. sorokiniana but harvesting the

Table 1: Comparison of the growth of Chlorella sorokiniana and Ankistrodesmus falcatus in BBM and PM under different light intensities.

\begin{tabular}{lccccc} 
& \multicolumn{4}{c}{ Optical density $(\mathbf{6 6 0} \mathbf{~ n m})$} \\
\cline { 2 - 3 } & \multicolumn{2}{c}{ Chlorella sorokiniana } & & Ankistrodesmus falcatus \\
\cline { 2 - 3 } \cline { 5 - 6 } & BBM & PM & & BBM & PM \\
702 & $0.658 \pm 006$ & $1.123 \pm 0024$ & & $0.404 \pm 001$ & $0.991 \pm 002$ \\
1307 & $0.804 \pm 008$ & $1.333 \pm 001$ & & $0.682 \pm 001$ & $1.0 \pm 001$ \\
1786 & $1.2 \pm 0112$ & $1.48 \pm 001$ & & $1.002 \pm 0112$ & $1.002 \pm 001$ \\
\hline
\end{tabular}

BBM: Bold's Basal medium, PM: Poultry medium

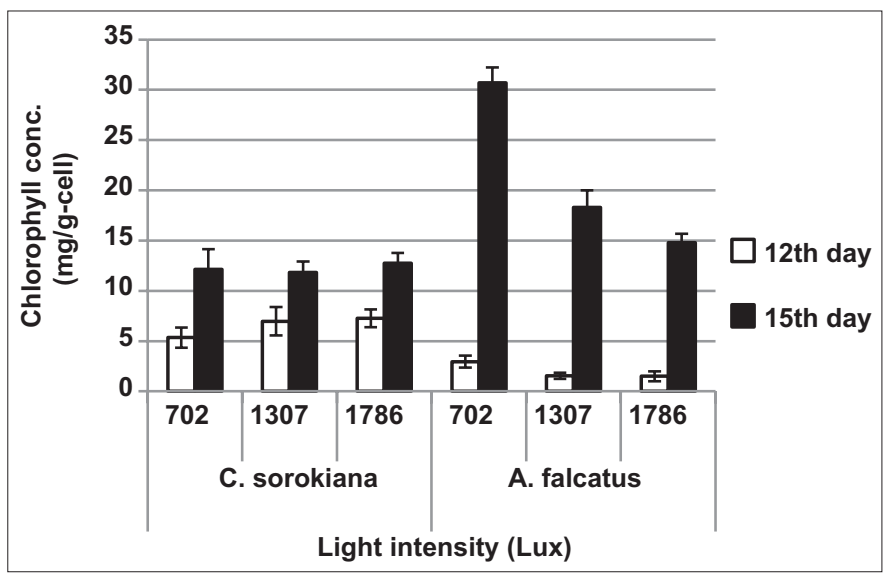

Figure 3: Effect of light intensity on chlorophyll-a production by Chlorella sorokiniana and Ankistrodesmus falcatus in Bold's Basal medium. biomass after 12 days of growth gave higher chlorophyll-a contents than harvesting after 15 days. In the case of A. falcatus, the highest chlorophyll-a content was obtained at the lowest light intensity (702 lux) from biomass harvested on day 15. As in the case of BB medium, increase in light intensity led to a reduction in the chlorophyll-a contents in A. falcatus. In other words, high light intensity inhibited chlorophyll-a synthesis in A. falcatus irrespective of the medium. As in the case of BBM, chlorophyll-a contents of A. falcatus were relatively higher than those of $C$. sorokiniana but chlorophyll-a contents of C. sorokiniana cultivated in PM were higher than those cultivated in BBM.

\subsection{Carotenoid Production in BBM}

The results of carotenoid production by $C$. sorokiniana and A. falcatus in BBM are shown in Figure 5. The carotenoid contents of the two microalgae harvested after 9 days of cultivation were very low. Day 12 was the optimum period for harvesting Chlorella biomass for carotenoid extraction in this study and the optimum light intensity was 1307 lux. This result is similar to the work of Jalal et al. [45], who reported that the carotenoid contents of the tropical marine microalgae Isochrysis sp. of biomass harvested from a 10-day-old culture grown at 1200 lux was the optimum. On the other hand, the highest carotenoid

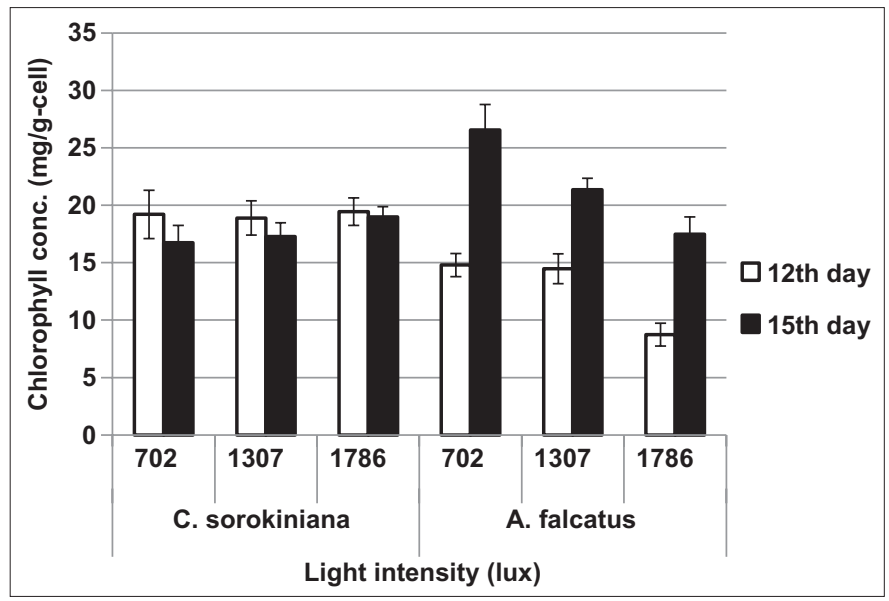

Figure 4: Effect of light intensity on chlorophyll-a production by Chlorella sorokiniana and Ankistrodesmus falcatus in poultry medium.

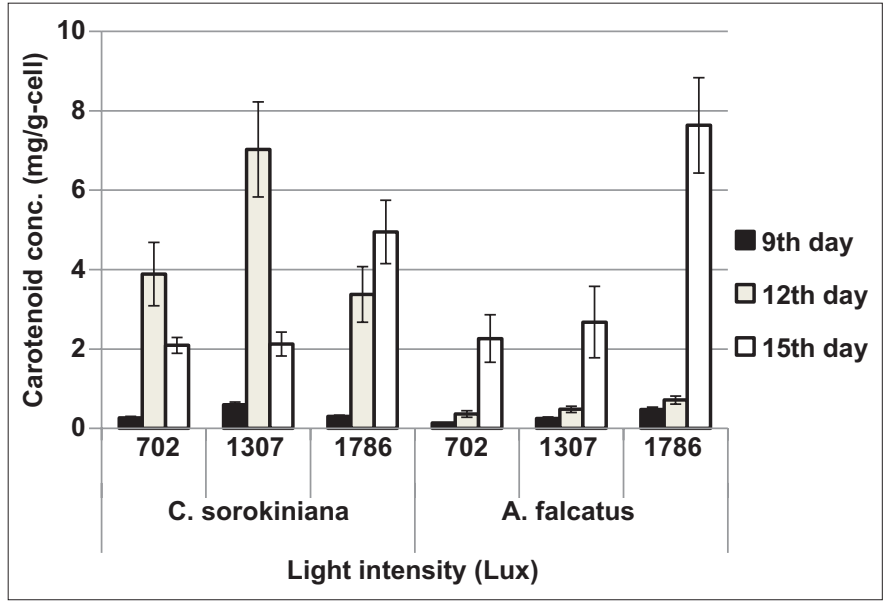

Figure 5: Effect of light intensity on carotenoid production by Chlorella sorokiniana and Ankistrodesmus falcatus in Bold's Basal medium. 
content was obtained from A. falcatus biomass cultivated at 1786 lux and harvested on the $15^{\text {th }}$ day. This shows that $C$. sorokiniana requires less cultivation time and a lower light intensity for carotenoid production than A. falcatus when grown in BBM. This result is also in line with that of Raman and Mohamad [46], who reported that cultivation of C. sorokiniana indoors favored astaxanthin production than outdoors. Cordero et al. [5] also reported that carotenoid production by $C$. sorokiniana was favored by a light intensity below $690 \mathrm{micromole} / \mathrm{m} / \mathrm{s}$. It is important to note that except for the highest light intensity (1786 lux), carotenoid contents of $C$. sorokiniana biomass were higher than those of Ankistrodesmus while chlorophyll-a contents of $A$. falcatus were higher than those of $C$. sorokiniana.

\subsection{Carotenoid Production in PM}

The results of carotenoid production by $C$. sorokiniana and A. falcatus in PM at different light intensities are shown in Figure 6. Carotenoid production by $C$. sorokiniana increased with increase in light intensity for the cells harvested on the $12^{\text {th }}$ day. However, the highest carotenoid content was obtained from biomass cultivated at 1786 lux and harvested after 15 days. This was the opposite of what was obtained in BBM culture and might be due to the turbidity of PM that shielded the alga from high light intensity. For the $A$. falcatus, the highest carotenoid was obtained after 12 days of cultivation at a light intensity of 1307 lux. This result is different from the results obtained in BBM. These results suggest that the length of time required for cultivating microalgae for carotenoid production varies from one microalga strain to another and it is also affected by the type of medium used. In PM, the carotenoid contents of $C$. sorokiniana were more than 4 times higher than those of $A$. falcatus under all the light intensities tested. Furthermore, PM favored carotenoid accumulation in C. sorokiniana more than BBM.

Although several growth media are employed in cultivation of microalgae, the choice of the medium to be used depends on the cost, target product(s), accessibility, and the choice of individual laboratory based on experience. BBM is widely used to cultivate fresh water microalgae because it contains the nutrients required for microalgae growth in the appropriate proportions [47]. In addition to the defined synthetic media, different agro-industrial wastes are also employed in microalgae cultivation to reduce cost. Such agricultural wastes include poultry droppings $[48,49]$, cow dungs, palm oil, and rubber industrial effluents [50]. It is interesting to note that in this study, PM supported better cell growth as well as chlorophyll-a and carotenoid accumulation than BBM. This is very significant considering that BBM is expensive

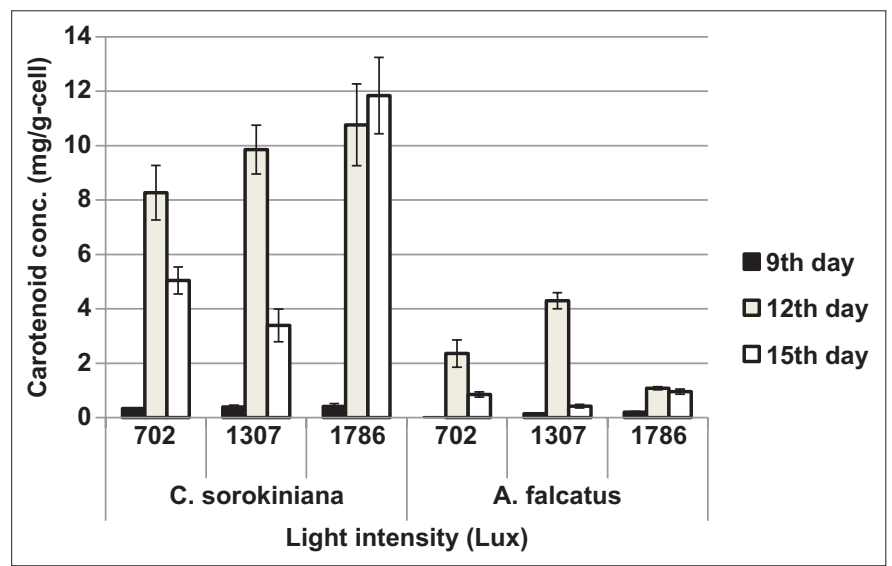

Figure 6: Effect of light intensity on carotenoid production by Chlorella sorokiniana and Ankistrodesmus falcatus in poultry medium. and not easily available in many developing countries. The use of PM will drastically reduce the cost of cultivating microalgae in developing countries and thus facilitate establishment of cottage microalgae cultivating industries in rural communities.

\section{AUTHORS' CONTRIBUTIONS}

Professor Nkechinyere O. Nweze conceptualized the research idea, provided the microalgae strains used in the study, and supervised the experiments; Jane Chizie Ogbonna carried out the literature review and performed the experiments; Dr. Christiana N. Ogbonna co-supervised the work and drafted the manuscript. All the authors read and agreed on the final version of the manuscript.

\section{AUTHOR CONTRIBUTIONS}

All authors made substantial contributions to conception and design, acquisition of data, or analysis and interpretation of data; took part in drafting the article or revising it critically for important intellectual content; agreed to submit to the current journal; gave final approval of the version to be published; and agree to be accountable for all aspects of the work. All the authors are eligible to be an author as per the international committee of medical journal editors (ICMJE) requirements/guidelines.

\section{FUNDING}

There is no funding to report.

\section{CONFLICTS OF INTEREST}

The authors report no financial or any other conflicts of interest in this work.

\section{ETHICAL APPROVALS}

This study does not involve experiments on animals or human subjects.

\section{PUBLISHER'S NOTE}

This journal remains neutral with regard to jurisdictional claims in published institutional affiliation.

\section{REFERENCES}

1. Hernandez D, Molinuevo-Salces B, Riano B, Larran-Garcia AM, Tomas-Almenar CT, Garcia-Gonzalez MC. Recovery of protein concentrates from microalgal biomass grown in manure for fish feed and valorization of the by-products through anaerobic digestion. Front Sustain Food Syst 2018;2:28.

2. Schade S, Meier T. Distinct microalgae species for food-part 1: A methological (top-down) approach for the life cycle assessment of microalgae cultivation in tubular photobioreactors. J Appl Phycol 2020;32:2977-95.

3. Schade S, Stangl GI, Meier T. Distinct microalgae species for foodpart 2: Comparative life cycle assessment of microalgae and fish for eicosapentaenoic acid (EPA), docosahexaenoic acid (DHA), and protein. J Appl Phycol 2020;32:2997-3013.

4. Cheng D, Li D, Yuan Y, Zhou L, Li X, Wu T, et al. Improving carbohydrate and starch accumulation in Chlorella sp. AE10 by a novel two-stage process with cell dilution. Biotechnol Biofuels 2017;10:75.

5. Cordero BF, Obraztsova I, Couso I, Leon R, Vargas MA, Rodriguez H. Enhancement of lutein production in Chlorella sorokiniana (Chlorophyta) by improvement of culture conditions and random 
mutagenesis. Mar Drugs 2011;9:1607-24.

6. Novoveska L, Ross ME, Stanley MS, Pradelles R, Wasiolek V, Sassi JF. Microalgal carotenoids: A review of production, current markets, regulations and future direction. Mar Drugs 2019;17:640.

7. Nwoba EG, Ogbonna CN, Ishika T, Vadiveloo A. Microalgal pigments: A source of natural food colors In: Alam A, Xu JL, Wang Z, editors. Microalgae Biotechnology for Food, Health and High Value Products. Germany: Springer; 2020. p. 81-123.

8. Ogbonna IO, Ogbonna JC. Isolation of microalgae species from arid environments and evaluation of their potentials for biodiesel production. Afr J Biotechnol 2015;14:1596-604.

9. Amin M, Chetpattananond P, Khan MN, Mushtaq F, Sami SK. Extraction and quantification of chlorophyll from microalgae Chlorella sp. IOP Conf Ser Mater Sci Eng 2018;414:012025.

10. Sangapillai K, Marimuthu T. Isolation and selection of growth medium for fresh water microalgae Asterarcys quadricellulare for maximum biomass production. Water Sci Technol 2019;80:2027-36.

11. Wells ML, Potin P, Craigie JS, Raven JA, Merchant SS, Helliwell KE, et al. Algae as nutritional and functional food sources: Revisiting our understanding. J Appl Phycol 2017;29:949-82.

12. Keller H, Reinhardt GA, Rettenmaier N, Schrb A, Dittrch M. Environmenat assessment of algae-based polyunsaturated fatty acid PUFA. In: PUFA Chain Project Reports, Supported by the EU's FP7 Under GA No. 613307. Heidelberg, Germany: IFEU-Institute of Energy and Environmental Research Heidelberg; 2017.

13. Borowitzka M. Commercial-scale production of microalgae for bioproducts. In: La barre S, Bates S, editors. Blue Biotechnology: Production and Use of Marine Molecules. Weinheim: Wiley-VCH; 2018. p. 33-65.

14. Khan MI, Shin JH, Kim JD. The promising future f microalgae: Current status, challenges, and optimization of a sustainable and renewable industry for biofuels, feed, and other products. Microb Cell Factories 2018;17:36.

15. Aratboni HA, Rafiei N, Garcia-Granados R, Alemzadeh A, MoronesRamirez JR. Biomass and lipid induction strategies in microalgae for biofuel production and other applications. Microb Cell Factories 2019;18:178.

16. Sayre R. Microalgae: The potential for carbon capture. Bio Sci 2010;60:722-7.

17. Begum H, Yusoff FM, Bannerjee S, Khatoon H, Shariff M. Availability and utilization of pigments from microalgae. Crit Rev Food Sci Nutr 2015;56:2209-22.

18. Cezare-Gomes EA, Mejia-da-Silva LC, Perez-Mora LS, Matsudo MC, Ferreira-Camargo LS. Potential of microalgae carotenoids for industrial application. Appl Biochem Biotechnol 2019;188:602-34.

19. Vadiveloo A, Nwoba EG, Ogbonna C, Mehta P. Sustainable production of bioproducts from wastewater-grown microalgae. In: Gayen K, Bhowmick TK, Maity SK, editors. Sustainable Downstream Processing of Microalgae for Industrial Application. United Kingdom: CRC Press, Taylor and Francis; 2019. p. 165-200.

20. Nwoba EG, Vadiveloo AA, Ogbonna CN, Ubi BE, Ogbonna JC, Moheimani NR. Algal cultivation for treating wastewater in African developing countries. A review. Clean (Weinh) 2020;48:2000052.

21. Fulke A, Chakrabarti T, Kannan K, Sivanesan S. $\mathrm{CO}_{2}$ Sequestration by microalgae: Advances and perspectives. In: Liu J, Sun Z, Gerken $\mathrm{H}$, editors. Recent Advances and Perspectives. United States: OMICS Group Incorporation; 2014. p. 1-7.

22. Pourjamshidian R, Abolghasermi H, Esmaili M, Amrei HD, Parsa M, Rezaei S. Carbon dioxide biofixation by Chlorella sp. In a bubble column reactor at different flow rates and $\mathrm{CO}_{2}$ concentrations. Braz $\mathrm{J}$ Chem Eng 2019;36:639-45.

23. Ong TM, Whong WZ, Stewart J, Brockman HE. Chlorophyllin: A potent antimutagen against environmental and dietary complex mixtures. Mutat Res 1986;173:111.
24. Ferruzi MG, Bohn V, Courtney PD, Schwartz SJ. Antioxidant and antimutagenic activity of dietary chlorophyll derivatives determined by radical scavenging and bacterial reverse mutagenesis assays. J Food Sci 2006;67:2589-95.

25. Ferreira VS, Sant'Anna C. Impact of culture conditions on the chlorophyll content of microalgae for biotechnological applications. World J Microbiol Biotechnol 2016;33:20.

26. Sarkar S, Manna MS, Bhowmick TK, Gayen K. Extraction of chlorophyll and carotenoids from dry and wet biomass of isolated Chlorella thermophila: Optimization of process parameters and modelling by artificial neural network. Process Biochem 2020;96:58-72.

27. Singh DP, Khattar JS, Rajput A, Chaudhary R, Singh R. High production of carotenoids by the green microalga Asterarcys quadricellulare PUMCC 5.1.1 under optimized culture conditions. PLoS One 2019;14:e0221930.

28. Ogbonna CN. Production of food colourant by Filamentous fungi. Afr J Microbiol Res 2016;10:960-71.

29. Ogbonna CN, Aoyagi H, Ogbonna JC. Isolation and identification of Talaromyces purpuorogenus and preliminary studies on its pigment production in solid state cultures. Afr J Biotechnol 2017;16:672-82.

30. Ambati RR, Gogisetty D, Aswathanarayana RG, Ravi S, Bikkina PN, Bo L, et al. Industrial potential of carotenoid pigments from microalgae: Current trends and future prospects. Crit Rev Food Sci Nutr 2017;59:1880-902.

31. Available from: https://www.marketsandmarkets.com/MarketReports/carotenoid-market-158421566.html. [Last accessed on 2020 Aug 05].

32. Singh M, Das KC. Low cost nutrients for algae cultivation. In: Bajpai R, Prokop A, Zappi M, editors. Starch Overproduction by Means of Algae. Netherlands: Springer; 2014. p. 69-82.

33. Sibi G. Low cost carbon and nitrogen sources for high microalgal biomass and lipid production using agricultural wastes. J Environ Sci Technol 2015;8:113-21.

34. Rogeri DA, Ernani PR, Mantovani A, Lourenco KS. Composition of poultry litter in Southern Brazil. Rev Bras Cienc 2016;40:e0140697.

35. Ogbonna JC, Yada H, Tanaka H. Kinetic study on light limited batch cultivation of photo synthetic cells. J Fermen Bioeng 1995;80:259-64.

36. Matos AP, Ferreira WB, Morioka LR, Moecke EH, Franca KB, Sant' Anna ES. Cultivation of Chlorella vulgaris in medium supplemented with desalination concentrate grown in a pilot-scale open raceway. Braz J Chem Eng 2018;35:1183-92.

37. Markou G, Iconomou D, Muylaert K. Applying raw poultry liter leachate for the cultivation of Arthrospira platensis and Chlorella vulgaris. Algal Res 2016;13:79-84.

38. Becker EW. Microalgae: Biotechnology and Microbiology. United Kingdom: Cambridge University Press; 1994. p. 293.

39. Branisa J, Jenisova Z, Porubska M, Jomova K. Spectrophotometric determination of chlorophylls and carotenoids. An effect of sonication and sample processing. J Microbiol Biotech Food Sci 2014;3:61-4.

40. Metsoviti MN, Pappoolymerou G, Karapanagiotidis IT, Katsoulas N. Effect of light intensity and quality on growth of Chlorella vulgaris. Plants Basel 2020;9:31.

41. Nzayisenga JC, Farge X, Goll SL, Sellstedt A. Effects of light intensity on growth and lipid production in microalgae grown in wastewater. Biotechnol Biofuels 2020;13:4.

42. Kumar V, Kumar A, Nanda M. Pretreated animal and human waste as a substantial nutrient source for cultivation of microalgae for biodiesel production. Environ Sci Pollut Res 2018;25:22052-9.

43. Wang Y, Liu S, Tian X, Fu Y, Jiang X, Li Y. Influence of light intensity on chloroplast development and pigment accumulation in the wild-type and etiolated mutant plants of Anthurium andraeanum Sonate. Plant Signal Behav 2018;13:e1482174. 
44. Kang D, Kim KT, Heo TY, Kwon G, Lim C, Park J. Inhibition of photosynthetic activity in wastewater-borne microalgal-bacterial consortia under various light conditions. Sustainability 2019;11:2951.

45. Jalal KC, Shamsuddin AA, Rahman MF, Nurzatul NZ, Rozihan M. Growth and total carotenoid, chlorophyll a and chlorophyll b of tropical microalgae (Isochrysis sp.) in laboratory cultured conditions. J Biol Sci 2019;13:10-7.

46. Raman R, Mohamad SE. Astaxanthin production by freshwater microalgae Chlorella sorokiniana and marine microalgae Tetraselmis sp. Pak J Biol Sci 2013;15:1182-6.

47. Iyovo DV, Guocheng D, Jian C. Poultry manure digestate enhancement of Chlorella vulgaris biomass under mixotrophic condition for biofuel production. J Microb Biochem Technol 2010;2:1000023.

48. Agwa OK, Abu GO. Utilization of poultry waste for the cultivation of
Chlorella sp. for biomass and lipid production. Int J Curr Microbiol Appl Sci 2014;3:1036-47.

49. Han X, Rusconi N, Ali P, Pagkatapunan K, Chen F. Nutrients extracted from chicken manure accelerated growth of microalga Scenedesmus obliquus HTB1 green sustain. Chem 2017;7:101-13.

50. Phang SM. Algal production from agro-industrial wastes in Malaysis. Sci Sustain Dev Ambio 1990;19:415-8.
How to cite this article:
Ogbonna JC, Nweze NO, Ogbonna CN. Effects of light on cell growth,
chlorophyll and carotenoid contents of Chlorella sorokiniana and
Ankistrodesmus falcatus in poultry dropping medium. J App Biol Biotech.
2021;9(2):157-163. DOI: 10.7324/JABB.2021.9215 